\title{
From the instantaneous corrosion rate to a representative value
}

\author{
C. Andrade, N. Rebolledo \& F. Pedrosa \\ Center for Safety and Durability of Structures and Materials (CISDEM-CSIC-UPM), Madrid, Spain
}

\begin{abstract}
Reinforcement corrosion develops due to the penetration of chlorides or of the carbonation front through the concrete pores and corrosion develops if enough moisture is present. However as the corrosion rate changes with temperature and the evolution of the corrosion itself, the representation may not be clear enough to be used for comparative purposes or for prediction of future evolution. The present work proposes a parallel use of accumulated corrosion depth, which is obtained by the integration of each age of the corrosion rate-time curve. This kind of representation enables the determination of corrosion depth at each age and appears the adequate to establish a Representative annual average value for comparative purposes. The procedure is applied to concrete specimens and real size elements exposed to Madrid outdoor conditions.
\end{abstract}

\section{INTRODUCTION}

Concrete structures may suffer reinforcement corrosion due to the penetration of carbonation or of chloride ions (Page et al. 1982). The onset of corrosion consists in the passage of the steel state from a passive or negligible corrosion rate to an active corrosion state identified visually by the appearance of rust with the corresponding loss of bar cross section or by the shifting of the corrosion rate from values below $0.1 \mu \mathrm{A} / \mathrm{cm}^{2}$ to above $0.2 \mu \mathrm{A} / \mathrm{cm}^{2}$ (Andrade et al. 1996). The corrosion rate is not commonly measured in spite of its importance to predict the evolution of the loss in structural load bearing capacity. This is due to the need of particular skills for the carrying out of the measurements and the need to use accurate portable corrosion rate meters (Andrade et al. 2004).

One of the difficulties in the interpretation is linked to the evolution of the values of the corrosion rate with the climate due to its dependence on the degree of concrete water saturation and on the temperature. This makes the corrosion rate to vary in a cyclic manner along the day and along the year following the seasons and the rain or snow events (Vennesland 1997) (Andrade et al. 2002).

On the other hand, in site-structures the usual is to measure the corrosion rate once or very few times. How to find a representative value with so few measurements made at a particular seasonal period? In present paper are presented two examples of variations of the corrosion rate in specimens exposed to natural atmospheres and how the trends are statistically treated in order to have a representative value of $I_{\text {corr.REP }}$ which could be used to characterize the particular structure and corrosion process. The treatment is made by calculating from the corrosion rate $I_{\text {corr, }}$ the accumulated corrosion penetration, $\mathrm{P}_{\text {corr, }}$ which has much less variation than the instantaneous corrosion rate.

\section{EXPERIMENTAL}

For the sake of the illustration, two cases were selected were: 1) concrete specimens exposed to natural environment in Madrid climate and that have been measured every week (Fig. 1) and 2) a beam that was measured periodically but no so frequently as the previous specimens (Fig. 2).

The small specimens were of cylindrical shape of $7.5 \mathrm{~cm}$ in diameter $\times 15 \mathrm{~cm}$ in height. They had a centred bar as shown Figure 1. The concretes used were prepared with an OPC (CEM I-42,5R), river siliceous sand $(0-6 \mathrm{~mm})$ and crushed granite $6-12 \mathrm{~mm}$ as coarse aggregate. They were cast in cylindrical moulds and the moulds placed in a chamber of $\mathrm{RH}>95 \%$ and $20 \pm 2^{\circ} \mathrm{C}$ during $24 \mathrm{~h}$. Then, they

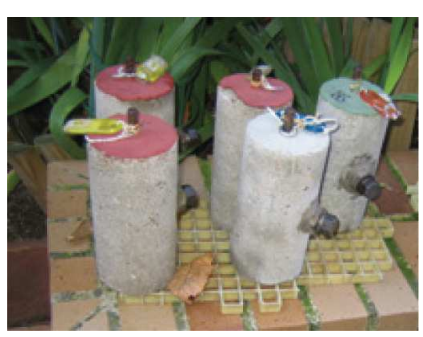

Figure 1. Concrete specimens exposed to the action natural atmosphere in Madrid-Spain. 

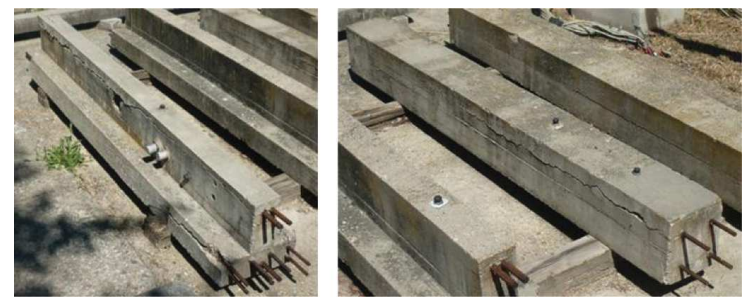

Figure 2. A view of the beam that is also exposed to the action of natural atmosphere.

were cured under water for other 2 days then were exposed to air in laboratory conditions ( $\mathrm{RH} \cong 50 \%$ and $20 \pm 2^{\circ} \mathrm{C}$ ) up to 28 days. After that curing period, specimens some (P-13) were carbonated in a chamber at $100 \%$ of $\mathrm{CO}_{2}$ and $60 \% \mathrm{RH}$ until increase of weight was less than $0.1 \%$. Full carbonation was required to allow for the active corrosion processes to occur. Specimen $\mathrm{P}-23$ having $3 \% \mathrm{CaCl}_{2}$ added in the mix was as corroding from its fabrication.

In order to obtain a cavity in which the internal Relative Humidity (RH-IN) could be measured holes were drilled in the specimens. A metallic tube was inserted to seal the walls in order to allow access of the water vapour only from the bottom of the cavity. The cavity remained sealed by a plug (Figure 1) between successive measurements. A suitable device (Vaisala humidity probe) having almost the same diameter than the cavity is introduced periodically in it to reach its bottom, thus to measure close to the steel bar.

All the specimens were introduced during their first year to different constant Temperature, $\mathrm{T}$, and RH chambers. After this year some of them were submitted to natural weathering in the Madrid climate. During this time, the internal (IN) and external (EXT) RH, T and weight, W, were monitored over time, together with the simultaneous measurement of corrosion potential, electrical resistivity and corrosion rate. For measuring the $\mathrm{RH}$ and $\mathrm{T}$, at the environment of the particular exposition ambient, a small hygrometric datalogger, was used to record the atmospheric evolution of $\mathrm{RH}$ and T (HOBO H08-003-02). The reference moisture conditions selected were: $\operatorname{dry}\left(40^{\circ} \mathrm{C}\right.$ until constant weight) and water saturated (full saturation under vacuum). The corrosion parameters were measured by means of a laboratory made potentiostat SVC-2. It uses a potentiostatic step with a waiting period of 30 seconds for making the Polarization Resistance measurements and applies the current interruption method for measuring the ohmic drop. The reference electrode is a saturated calomel electrode.

The big samples used for illustration were: a reinforced concrete T-beam (Andrade et al. 2002) and a square section pile, as illustrated in Figure 2. Both big specimens have been contaminated with
$3 \%$ chloride by weight of cement added to the mix in the form of $\mathrm{CaCl}_{2}$ to promote corrosion and were exposed outdoors to Madrid climate afterwards. The specimens are 2 meters in length.

For the corrosion measurements (corrosion potential $\mathrm{E}_{\text {corr, }}$, the resistivity, $\rho$ and the corrosion rate, $\mathrm{I}_{\text {corr }}$, in these big samples a portable corrosion rate meter, Gecor 08, was used, having modulated confinement of the current. The reference electrode used is $\mathrm{Cu} / \mathrm{CuSO}_{4}$. The relative humidity, and temperature, $\mathrm{T}$, were recorded in cavities of the concrete also drilling holes and inserting a metallic tube to isolate the lateral walls of the cavity.

\section{RESULTS}

Figure 1 depicts the RH/T-EXT values recorded during the five years period of exposure to Madrid climate. This town has a continental weather reaching temperatures around $0-5^{\circ} \mathrm{C}$ in winter and $35-40^{\circ} \mathrm{C}$ in summer.

The RH evolves from around $10 \%$ in summer to $60-70 \%$ in winter as average values. Raining may appear around 75-100 days per year with around 3155 hours/year of Time of Wetness, TOW and around $600-700 \mathrm{ml} / \mathrm{m}^{2}$ collected annually. Snow may occur one to two times per year.

In Figure 4 is shown the evolution of the instantaneous corrosion rate, $\mathrm{I}_{\text {corr }}$, from around the year 2000 of specimen 13 which is carbonated. In Figure 5 are given the corrosion rate values of the beam exposed in the same atmosphere of Madrid although from 1990 but registered from 1995. The $I_{\text {corr }}$ values of the beam and of the pillar are represented in the same Figure 6 but recorded only from 2010.

The trends show important changes due to the different seasons which mean different concrete

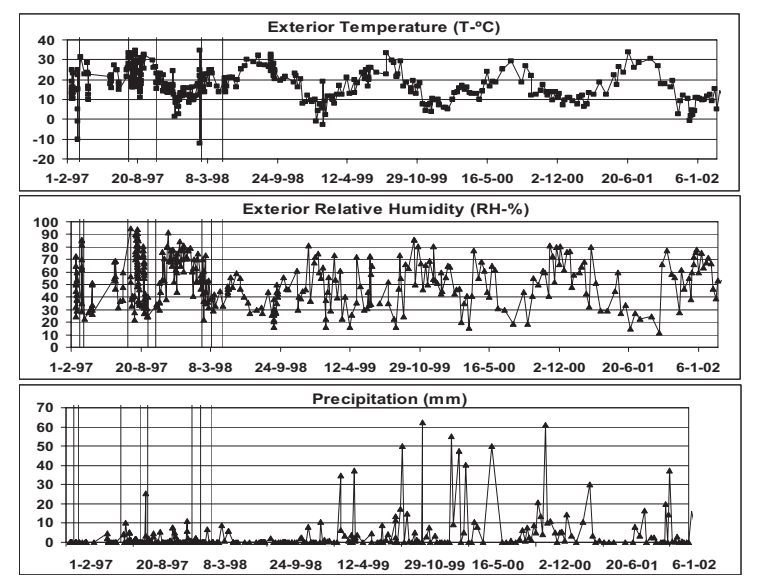

Figure 3. Evolution of relative humidity, temperature and rainfall in the atmosphere of Madrid. 


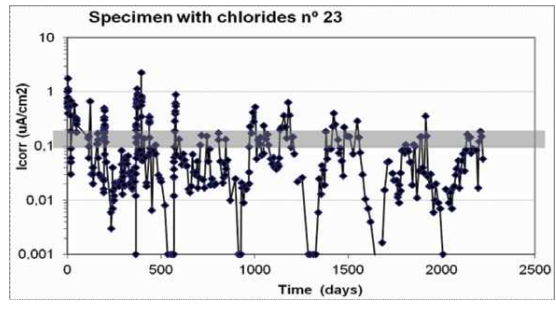

Figure 4. Evolution of instantaneous corrosion rate, $\mathrm{I}_{\text {corr }}$, of the specimen containing added chlorides.

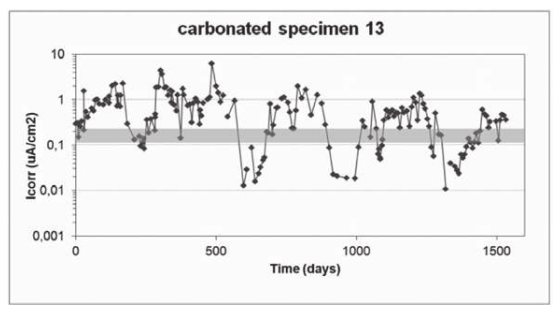

Figure 5. Evolution of the $\mathrm{I}_{\text {corr, }}$ of the carbonated specimen containing.

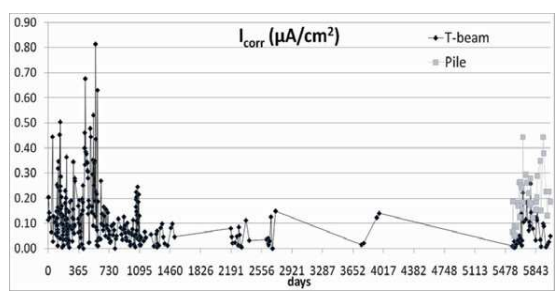

Figure 6. Values of the beam exposed to Madrid atmosphere from 1995 and those of the pillar from 2010.

moisture contents and temperatures. As all the samples are non sheltered from rain, they exhibit the higher $I_{\text {corr }}$ values in winter and spring presenting very low $I_{\text {corr }}$ values in summer due the drying induced by the higher temperatures. Temperature is the main controlling parameter of the concrete moisture which means that in hot weather the concrete dries and in winter with low temperatures, the concrete remains wet. This is opposite of what could have been expected as means that in hot weather the corrosion is smaller than in cold climates. In countries with low average temperature the water inside the concrete cannot evaporate and induces a longer "time of wetness". Nevertheless day cycles and seasonal cycles are reflected in the corrosion rate variations. On the other hand, the drying depth will depend on the length of dry periods and whether this length reaches the rebar level will vary with the cover depth. That is the cover depth is a the geometrical factor to be taken into account in the calculation of the time of rebar wetness.

\section{DISCUSSION}

The changes recorded as shown in Figures 4-6 are very difficult of being compared or interpreted. In Figures 7-10 are given the accumulated Corrosion penetration, $\mathrm{P}_{\text {corr }}$, values which result from the progressive integration of the instantaneous values.

The values of accumulated corrosion in Figures 9 and 10 are expressed in $\mu \mathrm{m} /$ year instead of $\mu \mathrm{A} / \mathrm{cm}^{2}$ in order to visualize that this parameter gives the loss in cross section calculated as homogeneous corrosion. The trends, from the very beginning, now appear much clearer because the corrosion penetration is progressive and show near a lineal increase with time. The increase in the case of the specimens reveals the effect of the wet season and of the hot one because a kind of "steps" appears in the increasing trend. They mean that the corrosion penetration slows down during the hot periods due to the drying of the concrete and accelerates during winter and wet periods in spite of the lower temperatures. The same steps appear in the case of the pile although the registered period is shorter.

From the slope of the accumulated or corrosion penetration $\left(\mathrm{P}_{\text {corr }}\right)$ is possible to obtain the representative corrosion rate, $\mathrm{I}_{\text {corr,REP, }}$ which can

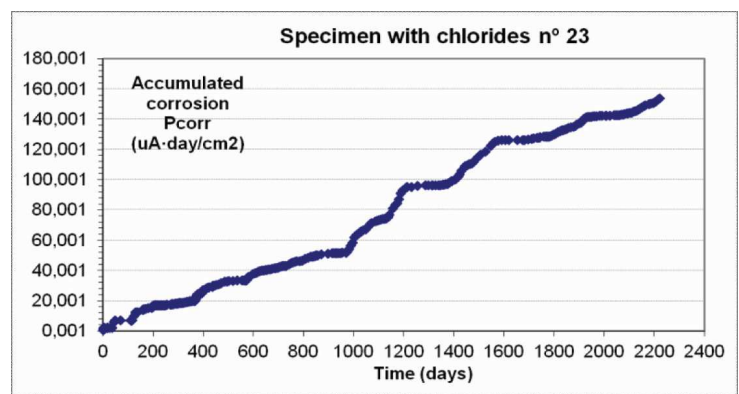

Figure 7. Accumulated corrosion, $\mathrm{I}_{\mathrm{acc}}$ or corrosion penetration depth with time of specimen containing chlorides added in the mix.

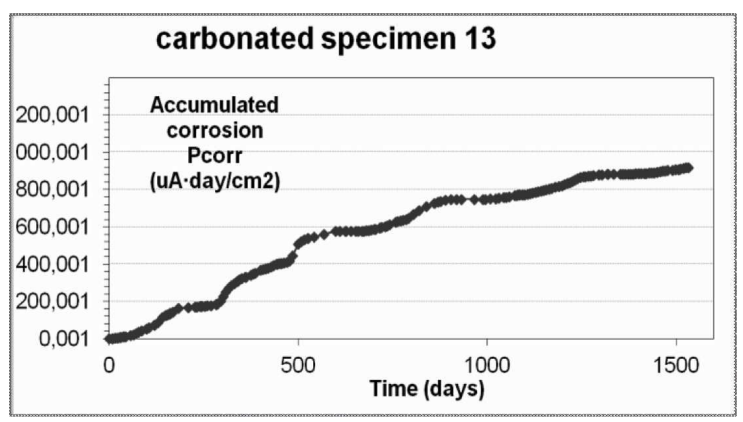

Figure 8. Accumulated corrosion, $\mathrm{I}_{\text {acc }}$, or corrosion penetration depth with time of carbonated specimen. 


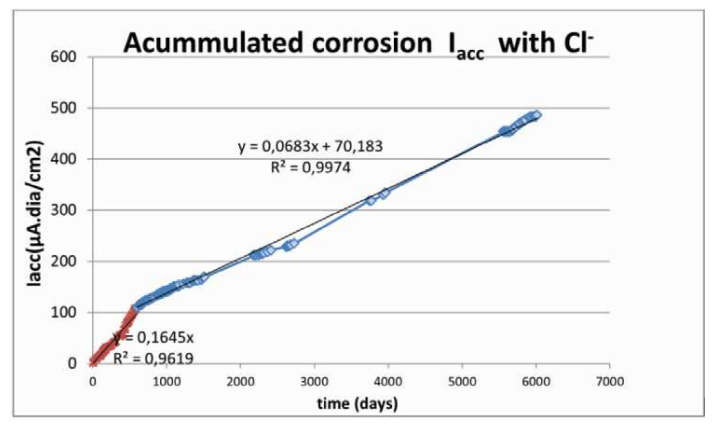

Figure 9. Accumulated corrosion, $I_{\text {acce }}$, or corrosion penetration depth with time of the beam with added chlorides.

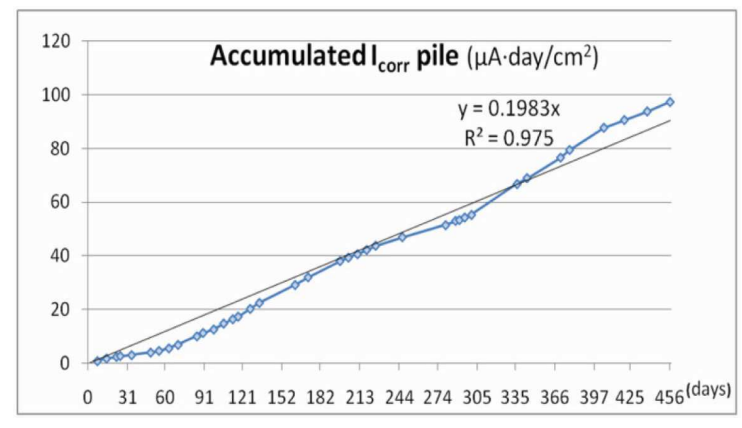

Figure 10. Accumulated corrosion, $\mathrm{I}_{\text {acc }}$, or corrosion penetration depth with time of the pillar with added chlorides.

Table 1. Descriptive statistics of the beam.

\begin{tabular}{|c|c|c|c|c|}
\hline \multirow[b]{2}{*}{$I_{\text {corr }}\left(\mu \mathrm{A} / \mathrm{cm}^{2}\right)$} & \multicolumn{2}{|l|}{ Period 1} & \multicolumn{2}{|l|}{ Period 2} \\
\hline & $\begin{array}{l}\text { Arithmetic } \\
\text { calculation }\end{array}$ & $\begin{array}{l}\text { From slope } \\
\text { figure } 9\end{array}$ & $\begin{array}{l}\text { Arithmetic } \\
\text { calculation }\end{array}$ & $\begin{array}{l}\text { From slope } \\
\text { figure } 9\end{array}$ \\
\hline \multicolumn{5}{|c|}{ Statistical treatment of the $I_{\text {corr }}$ values of the beam } \\
\hline Average value & 0.171 & 0.164 & 0.072 & 0.068 \\
\hline Std. deviation & 0.144 & & 0.059 & \\
\hline Coef. variation & $84.1 \%$ & & $82.2 \%$ & \\
\hline Regress. coef. & & 0.96 & & 0.99 \\
\hline
\end{tabular}

be used for prediction. They are given for the sake of illustration in Figures 9 and 10. It is interesting to note the two periods in the Representative or averaged corrosion rate, exhibited by the beam.

The difference of $I_{\text {corr, REP }}$ values between these two periods being the corrosion is higher in the first than in the second period, is attributed to that in the second period the cover is cracked and the drying is easier. Madrid has a dry atmosphere and then the wetness periods in concrete seem to be longer if the cover is not cracked. This hypothesis is confirmed in the case of the pile whose cover is much less cracked and its $I_{\text {corr. REP }}$ is in the level of the first period of that of the beam.

Regarding the statistical variation, in Table 1 is given the average values obtained from arithmetic calculation of the two periods of the beam and their standard deviation and coefficient of variation. They apparent scatter if high however if the statistical treatment is made on the accumulated corrosion penetration (as $\mathrm{I}_{\text {acc }}$ or $\mathrm{P}_{\text {corr }}$ in $\mu \mathrm{m}$ ) that scatter from a lineal behaviour (annual constant corrosion rate) is very much reduced as is given by the regression coefficients shown on Figures 9 and 10 which are very high and then indicating that the scatter is on the Instantaneous corrosion rate but the Representative value is very constant all over the life of the element. Then a Representative
Corrosion Rate value can be established with nominal very low scatter.

In the case of localized corrosion, it was previously demonstrated that this $\mathrm{I}_{\text {corr,REP }}$ should be multiplied by a pitting factor $\alpha$ whose recommended averaged value is 10 times (CONTECVET Manual).

\section{CONCLUSIONS}

The corrosion rate values. $\mathrm{I}_{\text {corr }}$, fluctuate considerably in outdoor exposition due to the rain periods and the temperature changes. The coefficient of variation found can be around $100 \%$.

However this apparently high scatter disappears when the accumulated corrosion penetration $\mathrm{P}_{\text {corr }}$ is calculated and from its slope an Averaged or annual Representative Corrosion Rate can be deduced with a very high regression coefficient of the fit in spite of the seasonal variations.

A final secondary, but important, observation of the elements containing chlorides exposed to natural atmosphere indicates that corrosion seems to develop differently after a certain level of cracking has been reached. It attenuates with time due to the increase of the concrete resistivity and possible more dry conditions when cracking favours it. 


\section{REFERENCES}

Andrade, C. \& Alonso, C. 1996. Construction and Building Materials, 10(5): 315-328.

Andrade, C., Alonso, C., Gulikers, J., Polder, R., Cigna, R., Salta, M., Raharinaivo, A. \& Elsener, B., (2004) RILEM Recommendation. Materials and Structures, 37: 623-643.

Andrade, C., Alonso, C. \& Sarría, J. 2002. Cement and Concrete Composites 24: 55-64.
CONTECVET. A validated user's Manual for assessing the residual life of concrete structures, www.ietcc.csic.es.

Page, C.L. \& Treadaway, K.W.J. 1982. Nature 297 (5862): 109-115.

Vennesland, O. 1997. Int. symposium on "Theory to Practice in Marine Environment, A.Blacknold Editor Norland: Norwegian Public Road Administration, Svolvaer-Norway: 253-262. 